\title{
El juego de chuncana entre los chimú. Un tablero de madera que prueba la hipótesis de Erland Nordenskiöld
}

Le jeu de chuncana de l'époque Chimú. Une planche en bois à l'appui de l'hypothèse de Erland Nordenskiöld

The chuncana game among the Chimu. A game board that proves the hypothesis of Erland Nordenskiöld

\section{Carmen Arellano Hoffmann}

\section{OpenEdition}

Journals

Edición electrónica

URL: http://journals.openedition.org/bifea/6360

DOI: $10.4000 /$ bifea. 6360

ISSN: 2076-5827

Editor

Institut Français d'Études Andines

Edición impresa

Fecha de publicación: 1 septiembre 2003

Paginación: 317-345

ISSN: 0303-7495

Referencia electrónica

Carmen Arellano Hoffmann, «El juego de chuncana entre los chimú. Un tablero de madera que prueba la hipótesis de Erland Nordenskiöld », Bulletin de l'Institut français d'études andines [En línea], 32 (2) | 2003, Publicado el 08 agosto 2003, consultado el 10 diciembre 2020. URL : http:// journals.openedition.org/bifea/6360; DOI : https://doi.org/10.4000/bifea.6360

\section{(c) (†) $\odot$}

Les contenus du Bulletin de l'Institut français d'études andines sont mis à disposition selon les termes de la licence Creative Commons Attribution - Pas d'Utilisation Commerciale - Pas de Modification 4.0 International. 


\title{
EL JUEGO DE CHUNCANA ENTRE LOS CHIMÚ UN TABLERO DE MADERA QUE PRUEBA LA HIPÓTESIS DE ERLAND NORDENSKIÖLD*
}

\author{
Carmen ARELLANO HOFFMANN**
}

\section{Resumen}

A principios del siglo XX el antropólogo sueco Nordenskiöld describe un tipo de juego que los indígenas del Chaco practican al final de la época de lluvias, en el mes de marzo. Nordenskiöld plantea la hipótesis de que tal juego es de origen andino. Añadiendo nuevas pruebas lingüísticas y etnológicas, así como la aplicabilidad de las reglas del referido juego del Chaco, la autora trata de demostrar, basándose en un estudio iconográfico, que un tablero de juego de la época chimú que se encuentra en el Museo Linden, Alemania, podría probar la hipótesis de Nordenskiöld.

Palabras claves: Juegos, Chimú, Chaco, Andes, ritos, fertilidad, iconografía.

\section{LE JEU DE CHUNCANA DE L'ÉPOQUE CHIMÚ UNE PLANCHE EN BOIS À L'APPUI DE L'HYPOTHÈSE DE ERLAND NORDENSKIÖLD}

\section{Résumé}

Au début du 20ème siècle l'anthropologue suédois Erland Nordenskiöld décrivit une forme de jeu pratiqué par les indigènes de la région de Chaco à la fin de la saison des pluies au mois de mars. Nordenskiöld soutient l'hypothèse que ce jeu pourrait avoir ses origines dans les Andes. L'auteur établit la probabilité de cette hypothèse en se basant sur l'analyse iconographique d'une planche en bois d'un jeu de l'époque Chimú, planche qui appartient à la collection du Musée Linden en Allemagne. L'auteur apporte des arguments linguistiques et éthnologiques supplémentaires, comme une description des règles du jeu, ce qui appuie l'hypothèse de Nordenskiöld.

Mots clés : Jeux, Chimú, Chaco, Andes, fertilité, rituels, iconographie.

\footnotetext{
* Este artículo es la versión castellana ampliada, actualizada y corregida del original en alemán publicado en la revista Tribus, $n^{\circ}$ 43, 1994 del Museo Etnológico de Stuttgart. Agradezco a las señoritas Adriana Zuluaga y Susanne Hatzingen por la traducción del mismo.

${ }^{* *}$ Smithsonian National Museum of the American Indian. E-mail: Arellanoc@ nmaicrc.si.edu
} 


\title{
THE CHUNCANA GAME AMONG THE CHIMU. A GAME BOARD THAT PROVES THE HYPOTHESIS OF ERLAND NORDENSKIÖLD
}

\begin{abstract}
In the beginning of the $20^{\text {th }}$ century, the Swedish anthropologist Erland Nordenskiöld described a game played by the indigenous people of the Chaco Region at the end of the rainy season (March). Nordenskiöld asserts as a hypothesis that game might have its origins in the Andes. The authors proves that hypothesis correct using an iconografic analysis of a wooden game board of the Chimu culture that is in the collection of the Linden Museum in Germany. The author presents additional linguistic and ethnological arguments as well as a game description that supports Nordenkiöld hypothesis.
\end{abstract}

Key words: Games, Chimu, Chaco, Andes, fertility, rituals, iconography.

En el año de 1910, Erland Nordenskiöld publicó un artículo sobre juegos y utensilios de juego del Gran Chaco. Su descripción de un campo de juego me permitió asociarlo a un objeto de madera que había visto en 1989 en la sala de exhibiciones sobre el Perú antiguo en el Museo Linden de Stuttgart, Alemania. En ese entonces me había preguntado por el uso que tal objeto habría tenido. Partiendo de la hipótesis de Nordenskiöld sobre el origen de este juego del Chaco, quisiera establecer una relación con el objeto de madera de ese museo.

El campo de juego de los indios del Chaco se dibuja simplemente en el piso y varía un poco de tribu a tribu. El grupo Chané tiene por ejemplo un campo de juego con 23 huecos (Fig. 1) (1). Los agujeros \# 1 y \# 23 son los puntos de partida de los contrincantes y se llaman "ó" (Nordenskiöld, 1910: 428 ) (2). En el año de 1918, Nordenskiöld menciona a la ligera que aquellos hoyos se llaman "casa", que en su opinión es un término usado por la mayoría de los grupos del Chaco (3).

Los hoyos intermedios, o sea los hoyos número 2 al 11 y del 13 al 22 se llaman “ápo" (Nordenskiöld, 1910: 428). En ensayos posteriores, Nordenskiöld no utiliza más este término, en lugar de ello va a usar la palabra "ovejas". La impresión que nos da Nordenskiöld es que este último vocablo está bastante difundido en la zona del Chaco más que la palabra "apo" (Nordenskiöld, 1918: 167; 1919: 155).

(1) El número de hoyos difiere de tribu en tribu (Nordenskiöld, 1910: 168; 1918: 429; 1919: 156).

(2) El autor escribe en 1919 (p. 155), en una nota de pie de página, que la palabra “ó" significa casa para los chané, los tapieté y los chiriguano.

(3) Es recién en 1919 que Nordenskiöld especifica que "ó" significa "casa" (ver nota de pie de página anterior) (Nordenskiöld, 1918: 167; 1919: 153, 155). 


\section{$\begin{array}{lllllllllllllllllllllll}1 & 2 & 3 & 4 & 5 & 6 & 7 & 8 & 9 & 10 & 11 & 12 & 13 & 14 & 15 & 16 & 17 & 18 & 19 & 20 & 21 & 22 & 2\end{array}$ \\ $\cdot|||||||||\cdot||||||||| \cdot$}

Fig. 1 - Counting board. Chané (Nordenskiöld, 1910: 428).

El hoyo central o el número 12 es nombrado “ö", que significa "río". Esta es la única palabra que traduce Nordenskiöld en su temprano artículo de 1910 y cuyo significado mantiene en sus posteriores comentarios (Nordenskiöld, 1910: 428) (4).

Los instrumentos de juego son: varillas, tallos y cuatro palos de madera (Fig. 2) que tienen la función de dados. Estos "dados" presentan un dibujo inciso en forma de zigzag o rombos en el lado convexo, el otro lado es cóncavo o plano (Nordenskiöld, 1910: 428). La distribución de los agujeros, así como el diseño en los palitos de juego de madera muestran una similitud desconcertante con el utensilio de madera del Museo

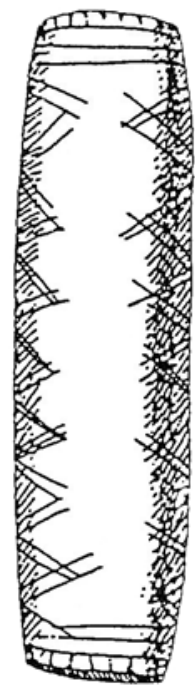

a

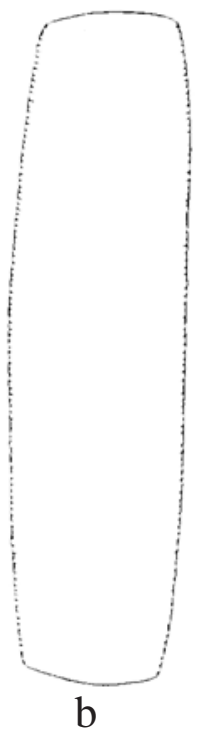

b

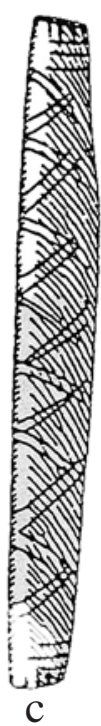

c

Fig. 2 - Dados. Ashlusla (Nordenskiöld, 1910: 428).

(4) Este mismo indica en 1918 , en la página 167 , nota de pie de página 2, que obtuvo todos los términos en español. Como se observa, no existe claridad con respecto a sus fuentes, si los indios del Chaco usaban ya en ese entonces solamente expresiones españolas, o si los términos que proporciona fueron traducciones de sus informantes (véase 1919: 155, nota de pie de página 1). 
Linden de Stuttgart, motivo por el cual nos preguntamos si se trata de la "prueba" a la teoría de Nordenskiöld de que tal juego del Chaco tuvo su origen en los Andes.

\section{EL TABLERO DE JUEGO DE LOS CHIMÚ}

Este objeto tiene el número de inventario 119537 (Fig. 3) (5) y proviene de una colección privada (6). Esta circunstancia nos impide conocer el contexto del hallazgo. En el libro de inventario sólo se especifica el nombre del país de procedencia y se da una explicación de su posible función: barra de balanza o ábaco.

El tablero es de madera negra y tiene las siguientes medidas en centímetros:

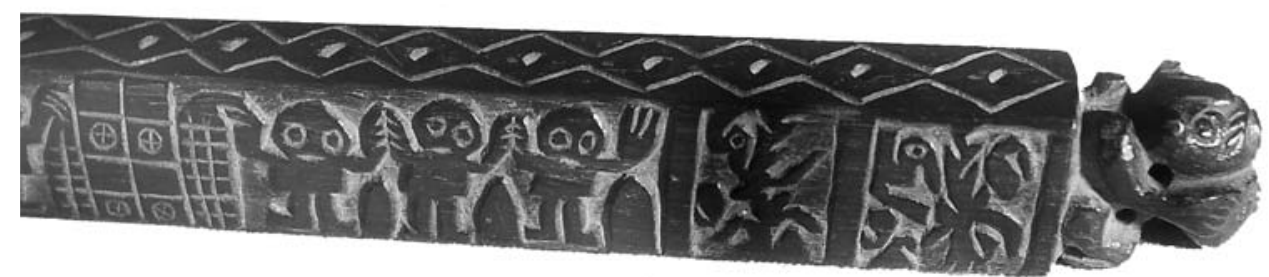

Fig. 3 - Linden Museum, U. Didoni.

27,5 de largo, 2,5 de alto, y 1,5 de profundidad. Su forma es la de un prisma cuadrangular. La superficie de los cuatro lados muestra un relieve plano ricamente tallado. En dos de los lados paralelos se puede reconocer la siguiente distribución de motivos: dos zonas (Figs. 4 y 5) en las partes extremas del objeto están separadas del centro por una línea gruesa. En aquellas están representados pájaros y plantas con frutas maduras. Considerando la forma de la fruta, se podría decir que se trata de mates (Lagenaria siceraria), pero la forma de las plantas indica que se trata del maíz (Zea mays). Las frutas mencionadas no serían entonces mates sino mazorcas especialmente opulentas. Asimismo lo que podría ser interpretado en un primer vistazo como el típico cuello doblado del mate, debe ser entendido como las barbas del maíz.

En la sección central del diseño tallado, se hallan seis figuras humanas con los brazos extendidos. En los rostros falta la nariz. Dos de estas figuras tienen en la mano un objeto, el cual puede ser interpretado como sonajas o cascabeles (7). Entre las figuras se ven motivos cónicos; algunos de ellos tienen escalones o puntas. Las seis

(5) Agradezco al Sr. Dr. Axel Schulze-Thulin, en aquel entonces conservador de la sección América, por haberme permitido el estudio del objeto y el dibujo del mismo. Asimismo, agradezco al Sr. Bless, antiguo administrador del depósito, por su amable ayuda. 2209/056).

(6) Colección Arthur Speyer, adquirida por el museo el día 14-3-1953 (número de lista

(7) El arqueólogo berlinés/boliviano Carlos Zalles Flossbach (=) consideró que tales instrumentos podrían ser látigos (carta a la autora del 7-12-1992). Quiero aprovechar la ocasión para agradecer sus valiosas observaciones al texto. 

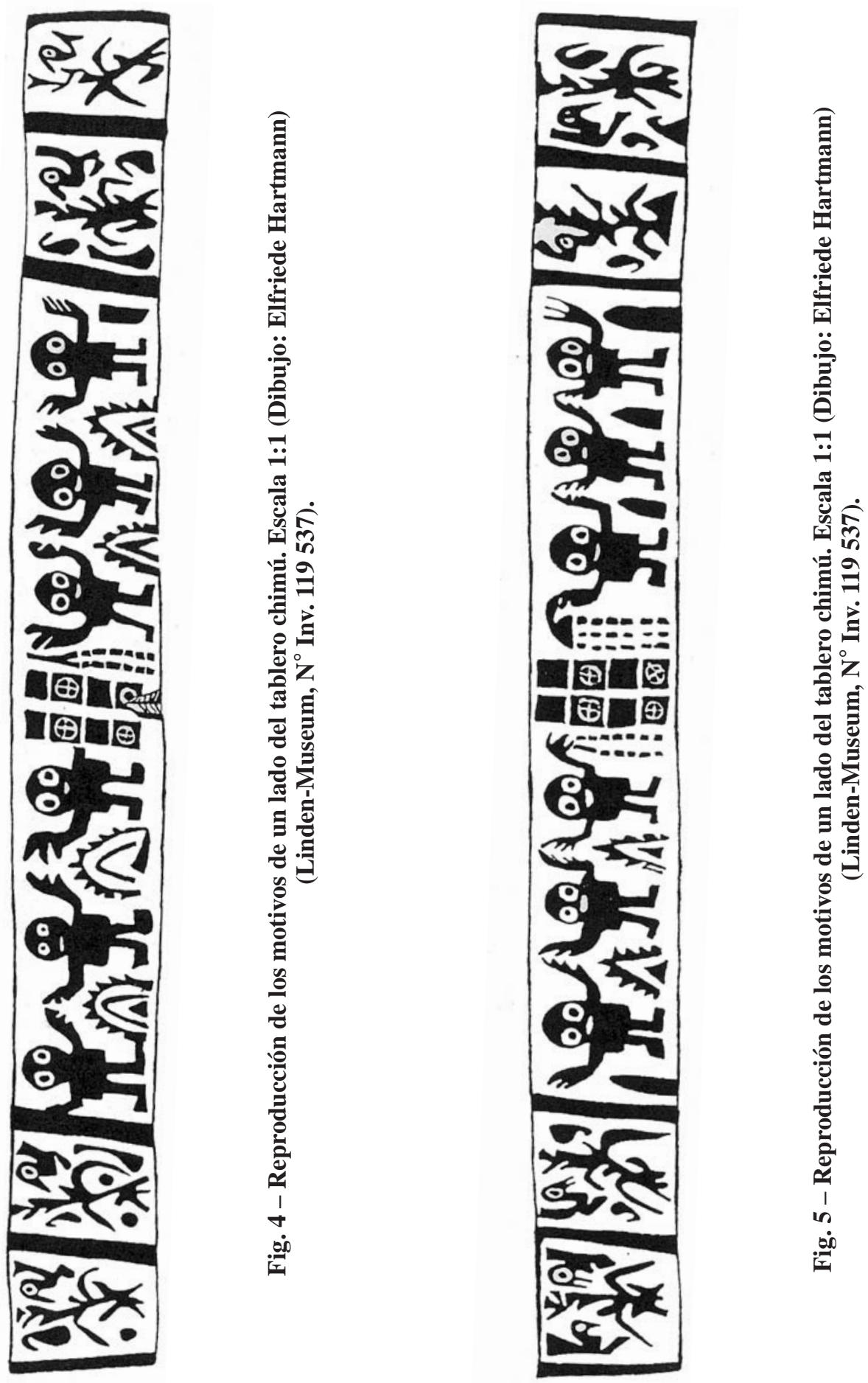
figuras están separadas en dos grupos, cada uno de tres figuras, por dos líneas de cuatro cuadrángulos cada uno. Tres cuadrángulos tienen en el medio un círculo con una cruz. El cuarto solamente muestra un círculo. Al otro lado del objeto, el círculo es reemplazado por un aspa (cómparese las figuras 4 y 5).

Como las plantas y los pájaros están separados de las figuras humanas por líneas gruesas, es evidente entonces que se está aludiendo a una representación consciente de dos niveles, a los que se les puede llamar también "mundos". La imagen con pájaros y frutas es fácil de interpretar como el mundo de los hombres. Las figuras en el centro son entes que pertenecen a otro nivel del ser: como no tienen nariz, hay que entenderlos como los antepasados o las almas de los muertos. Los brazos extendidos pueden estar indicando la posición que toman al danzar. Esta interpretación se funda en ilustraciones que se encuentran muchas veces en vasijas mochica (ver Figs. 6a-d), lo que está indicando la antigüedad de tal tipo de ilustraciones. Aquí los antepasados están señalados como esqueletos que bailan y tocan música. Por ser esqueletos, se muestran solamente las cavidades oculares y la bucal, faltando la nariz. La cultura Chimú, como sucesora y heredera de la cultura Moche, parece haber simplificado estos motivos, como lo explicaré más adelante cuando trate de la iconografía chimú.

La similitud anteriormente citada con el juego del Chaco se muestra en los otros lados paralelos del objeto de madera, que están dotados con un diseño de rombos y una serie de huecos (Fig. 7), que son los mismos que se observan en los dados del juego del Chaco. En cuanto al tablero chimú, en medio de cada rombo se encuentra un hoyo. En total son 17 agujeros perforados. El hueco central está señalado con una incisión. Esta ranura no se encuentra en el otro lado (Fig. 8).

A los dos extremos del objeto se encuentran figuras plásticas de jaguares que sostienen una cabeza humana en sus garras (Fig. 9). Estas figuras también están provistas de agujeros: uno constituye el hocico del animal y, a cada uno de los flancos de las figuras, se encuentran dos hoyos adicionales (Fig. 10). El tablero de madera tiene en total 27 perforaciones (ver Fig. 11).

El estilo del tallado y el color indican que se trata de un objeto perteneciente a la cultura chimú (8). La representación de los pájaros y la manera de cómo han sido talladas las manos son características típicas de esta cultura ( $C f$. Inka-Perú, 1991, tomo 2: 232, 236, fotos 294 y 298). En la iconografía de los chimú se encuentran muy raras veces figuras que representen los ancestros, porque normalmente se representaba sólo personajes de alta posición social o deidades. Sin embargo, en una vasija de la cultura chimú, encontré una figura similar a los antepasados del tablero del juego (McClelland, 1990: 98, fig. 13). En esta vasija de cerámica, la figura del antepasado está inmerso dentro de un mundo marino o acuático, o sea, probablemente representando así el inframundo. La imagen de este antepasado muestra las mismas características que ya conocemos de nuestro tablero de juego: ausencia de nariz, grandes cavidades oculares y bucal, y brazos extendidos. Aquí tampoco se pueden reconocer más detalles anatómicos, lo que parece ser típico para los chimú a diferencia de las figuras mochicas en las que se aprecia claramente las costillas.

Como no se conoce el contexto arqueológico del hallazgo del tablero de juego,

(8) Carlos Zalles Flossbach (=) me confirmó esta clasificación. 


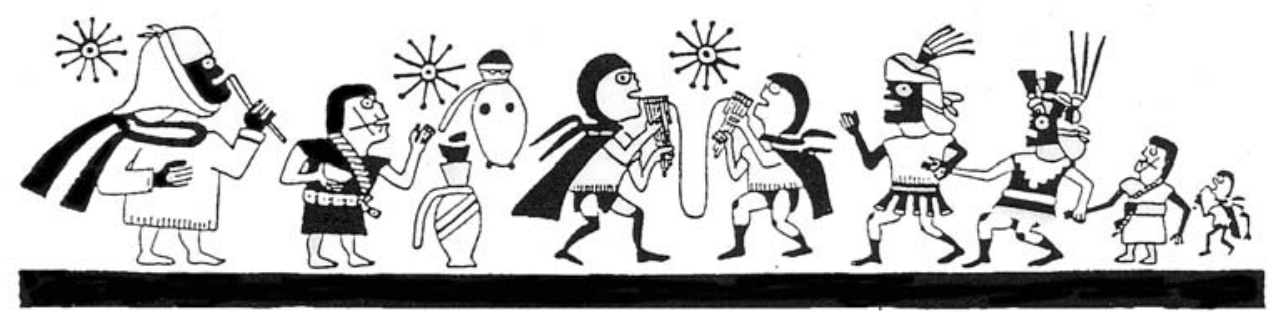

Fig. 6a - Fest der Totengeister (Fiesta de los espíritus) (Kutscher, 1950: 31).

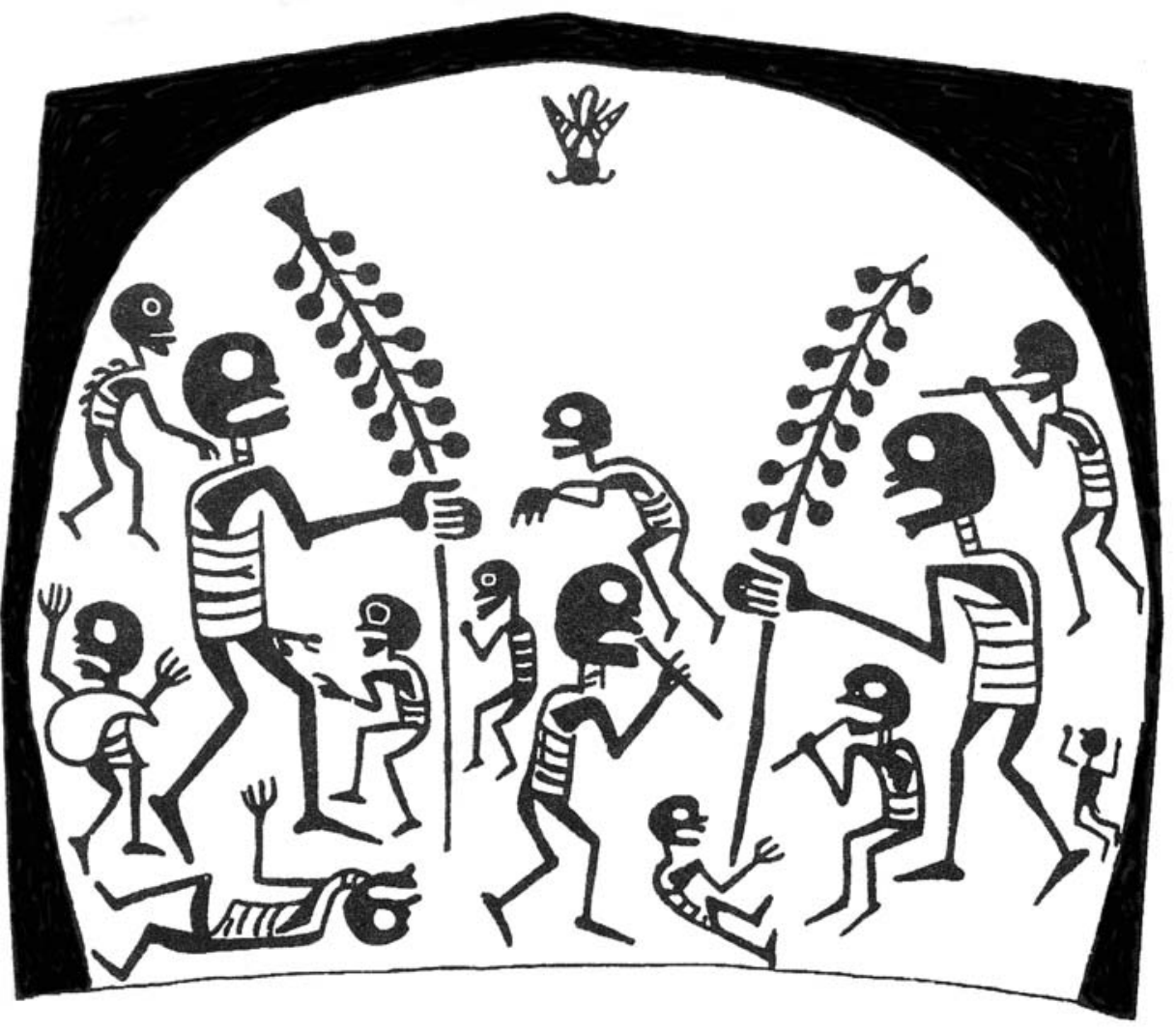

Fig. 6b - Totengeister mit Flöten und Rasselstäben (Espíritus con flautas y sonajeros) (Kutscher, 1950: 32). 

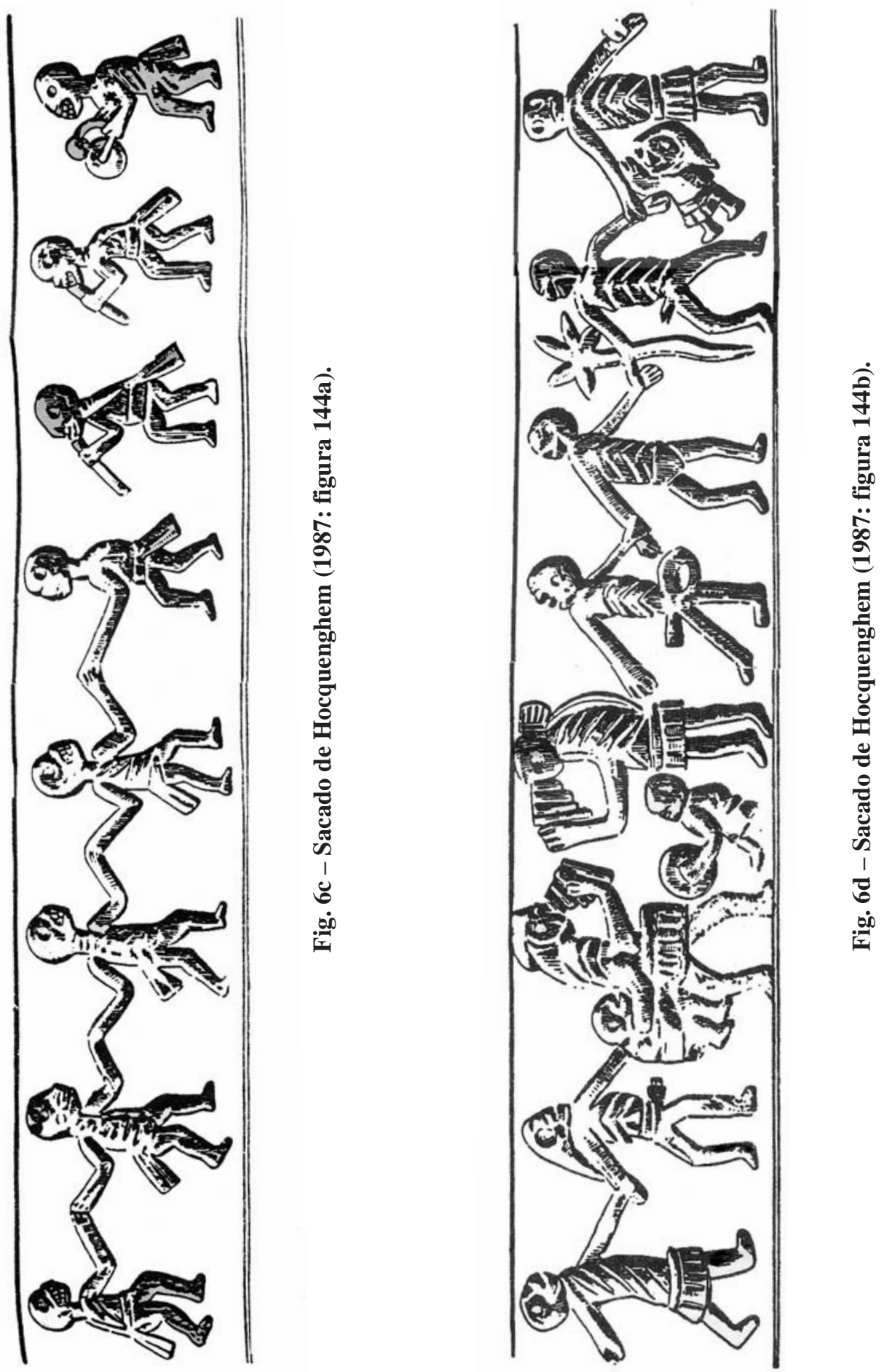

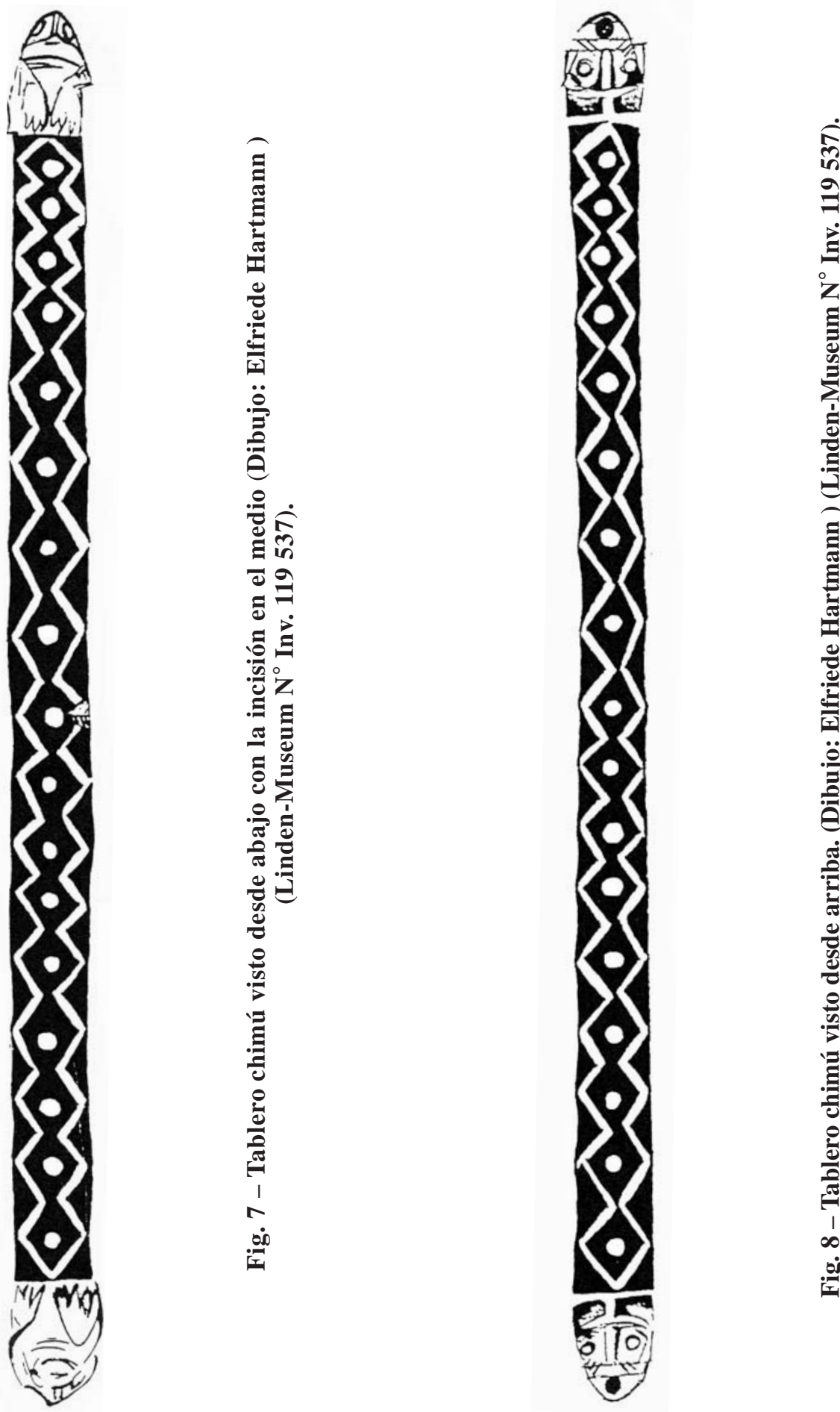

$\stackrel{\circ}{\underline{z}}$

$\dot{\mathrm{B}}$

号

E

远
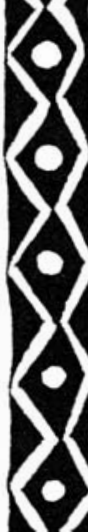

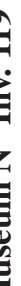

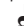

$\frac{\bar{e}}{3}$

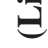

I

हี

줄

รั)

.

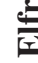

$\ddot{\circ}$

อ

ํㅡㄹ

릉

을

옹

光

0 


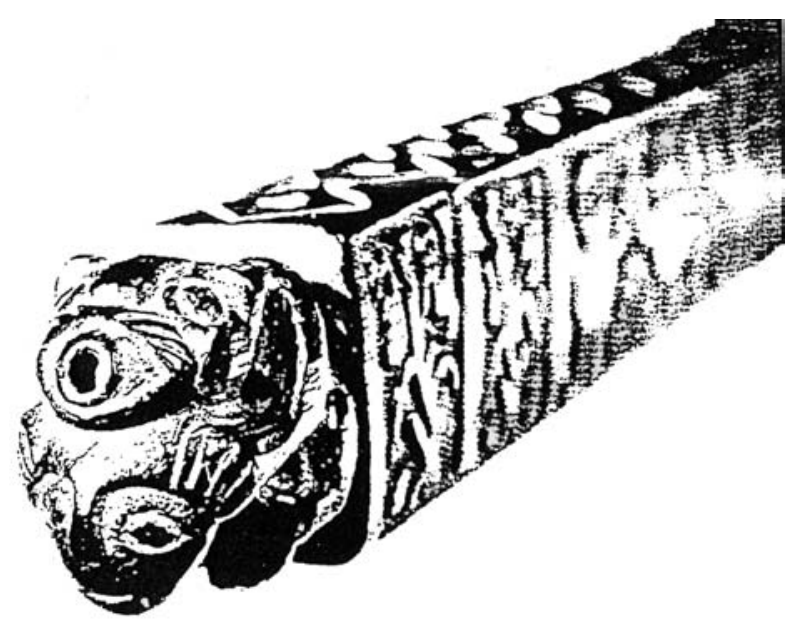

Fig. 9 - Linden-Museum, U. Didoni.

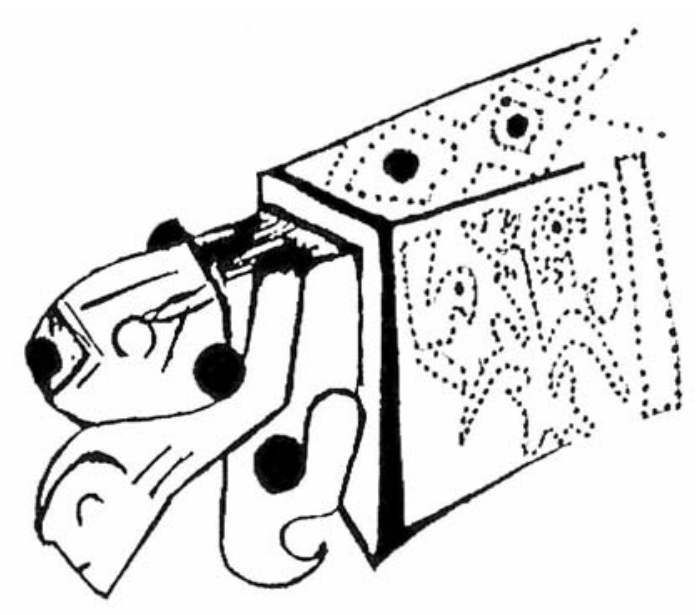

Fig. 10 - Jaguar tallado llevando en las garras una cabeza humana. Ormanento de uno de los extremos del tablero chimú (Dibujo: Elfriede Hartmann)

(Linden-Museum $\mathrm{N}^{\circ}$ Inv. 119 537). 
12

3

$\begin{array}{llll}6 & 7 & 8 & 9\end{array}$

$101112 \quad 13 \quad 14$

1516

$16 \quad 17 \quad 18$

1920212225

$23 \quad 24$

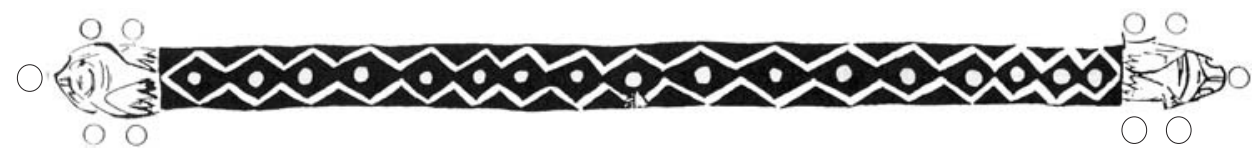

Fig. 11 - Disposición de los hoyos del tablero chimú (Dibujo: Elfriede Hartmann) (Linde-Museum $\mathrm{N}^{\circ}$ Inv. 119 537).

se hace difícil ubicarlo temporalmente dentro de las diversas fases de la cultura Chimú. El arqueólogo Michael Tellenbach del Reiss-Museum supone que el objeto puede clasificarse como Chimú tardío (9).

\section{2. ¿BARRA DE BALANZA, ÁBACO O TABLERO DE MADERA?}

Habiendo comparado ambos campos de juego, surge la pregunta: ¿señala la similitud un origen común? Para poder responderla, tenemos que descartar los otros supuestos sobre la función de este objeto, es decir, si el objeto chimú es una barra de balanza o un ábaco.

Para ser una barra de balanza, el objeto está tallado con demasiado primor (véase Figs. 1, 2, 4-8, 10), aunque se han encontrado barras de balanza con decoración tallada. Pero nuestra pieza en discusión presenta muchos más motivos que las que pudimos observar en las barras de balanza (compárese figuras 1 y 12). Espinoza Soriano nos muestra en su obra de 1987 algunos ejemplos de barras costeñas con relieves (Figs. 12a y b). Lamentablemente, el autor no proporciona las medidas de las balanzas, indicando escuetamente que son pequeñas y por ello utilizadas para pesar metales preciosos (Espinoza Soriano, 1987, tomo 1: 124-128). Las redes de otras balanzas pudieran estar señalando la posibilidad de que otro tipo de objetos haya sido también pesado. Por carecer de detalles descriptivos el trabajo de Espinoza, no podemos establecer muchas comparaciones con nuestro tablero. Por la figura 12a es posible, sin embargo, reconocer que las balanzas costeñas únicamente tienen 3 agujeros, por lo cual se diferencian sustancialmente de nuestro tablero. En los extremos de nuestro tablero no se encuentran las huellas de desgaste que las cuerdas tendrían que haber producido allí donde deberían de haber colgado de la barra. Los motivos ya sean de mates o de mazorcas de maíz tampoco admiten la posibilidad de que se hayan pesado tales frutos con el utensilio, pues para tal uso es demasiado pequeño. Por último, la iconografía del tablero es mucho más compleja y variada que las que se encuentran ilustradas en las figuras 12a y b. Por la forma del tablero, no se admite punto de comparación con otras balanzas conocidas de la época prehispánica y reproducidas en las figuras $12 \mathrm{a}$ y $\mathrm{b}$.

No hay ninguna relación directa entre los motivos del tablero y un posible uso

(9) Comunicación personal del 6 y 8 de octubre de 1993. 


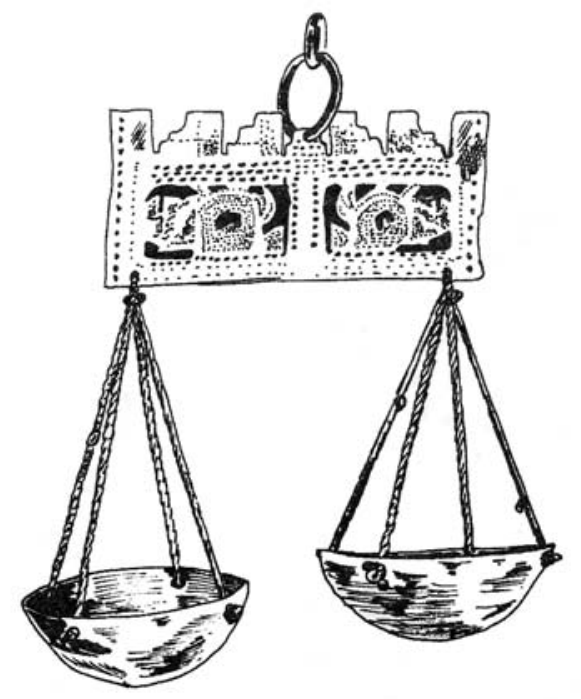

Balanza de platillos metálicos, procedente de la costa central del Perú.

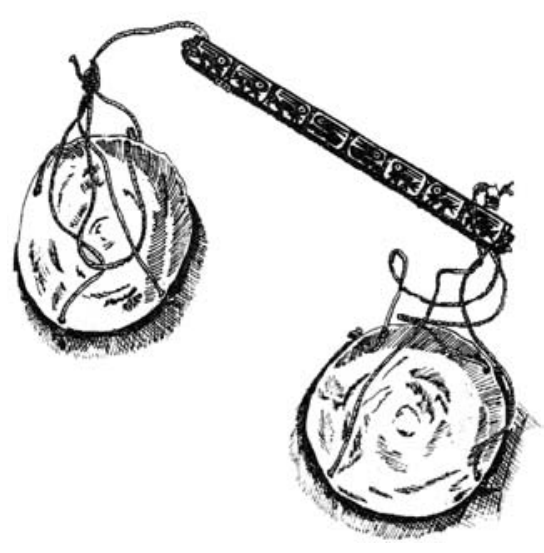

Balanza de platillos metálicos (cobre) usada por los orfebres del reino de Ishmay (Lima-

Pachacamac), siglo XV d. de C.

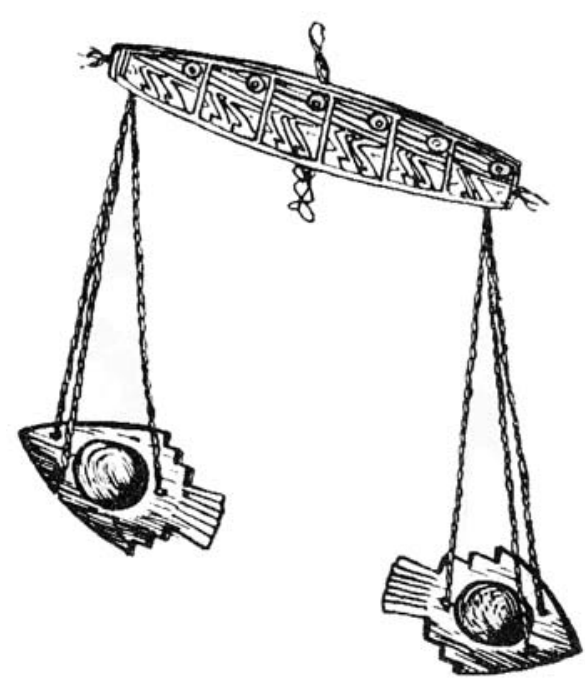

Balanza de madera para pesar oro.

Fig. 12a - Diversos tipos de balanzas

(tomado de Espinoza Soriano, tomo 1, 1987: 124-125). 


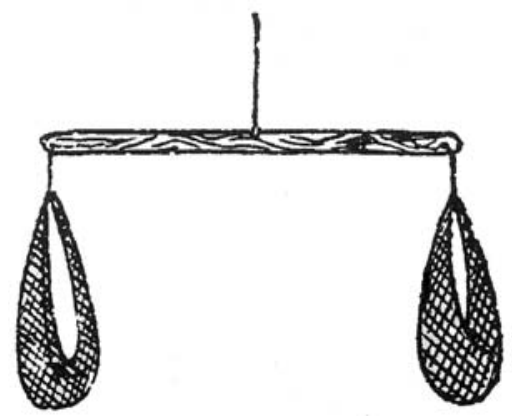

Balanza de redes.

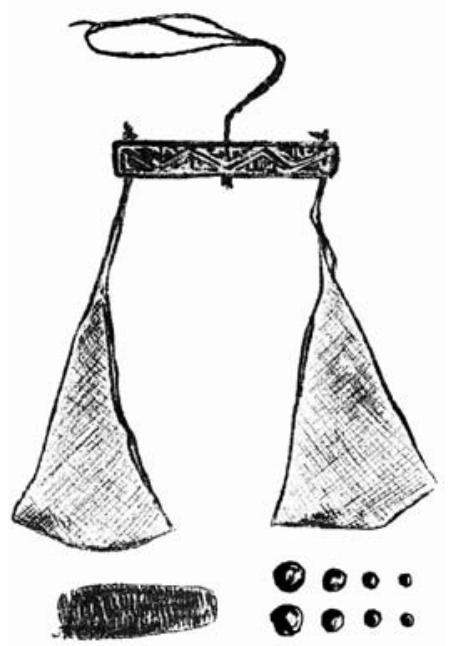

Balanza de redes con sus respectivas pesas consistentes en piedrecitas esféricas. Procede de Huacho.

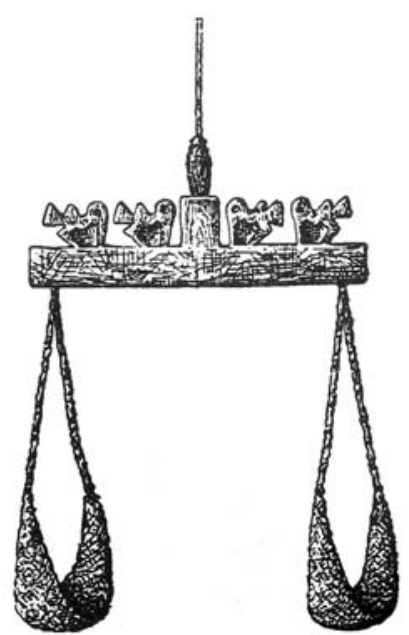

Balanza de redes procedente de Ancón.

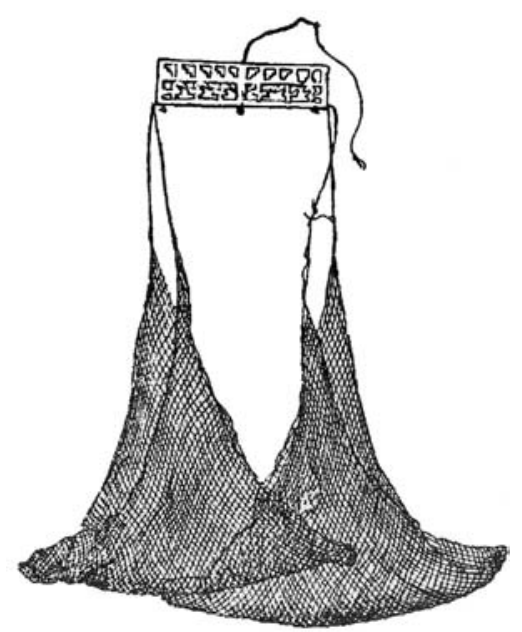

Otra balanza modelo redecilla, hallada en una excavación de la costa norte del Perú.

Fig. 12b - Diversos tipos de balanzas de redes (tomado de Espinoza Soriano, tomo 1, 1987: 126-127). 
como ábaco. La distribución de los huecos presenta, asimismo, la interrogante acerca de cómo ella haya permitido cálculos con el sistema decimal. En su reconstrucción del proceso de cálculo del ábaco antiguo peruano, Figge ya señala:

“... que todavía se confunden tableros de juego con tableros de cálculos [...] Un ábaco, funcione como funcione en forma particular, es [...] una 'calculadora', lo que significia que uno le introduce información y se reciben los deseados resultados de cálculo según manipulaciones prescritas [...] Por eso se puede decir que objetos con huecos más o menos profundos, no sirven de ábaco porque los reemplazos y desplazamientos, que son necesarios en el proceso de calcular, gastarían demasiado tiempo." (Figge, 1987: 144, 146-147) (10)

Esta aclaración apoya mi suposición de que el objeto del Museo Linden no es un utensilio de cálculo debido a que los hoyos son demasiados profundos y pequeños para permitir la entrada de una o más piezas de cálculo.

\section{ORIGEN ANDINO DEL JUEGO}

Cuando Nordenskiöld describió el juego en 1910 no era consciente, como él mismo declara, de que los indios del Chaco lo hayan podido aprender de los indios de los Andes (Nordenskiöld, 1918: 166). El llegó a este convencimiento sólo cuando Rivet y Verneau describieron ciertos objetos provenientes del Ecuador sin poderlos clasificar (Rivet \& Verneau, 1912: 244; Nordenskiöld, 1918: 166), asentando así la hipótesis que tales objetos serían mesas de juego (Fig. 13). En aquellas vio una relación al juego de los indios del Chaco y supuso que estas "mesas de juego [de forma cuadrangular] podrían haber sido utilizadas para un juego semejante" (Nordenskiöld, 1918: 170; compárese con Smith, 1977). Aunque es muy difícil relacionar tales mesas de juego con el campo de juego de los indios del Chaco por la forma y la disposición distinta de los huecos, existen sin embargo otras referencias en Nordenskiöld que confirman la hipótesis de que el juego no es oriundo del Chaco sino de los Andes.

En 1918 Nordenskiöld opinó que el nombre del juego como la forma de contar deberían tener un origen quechua porque las palabras para los números tienen semejanza con las del idioma quechua. Aparte, existen en los idiomas de las tribus del Chaco otras palabras para los mismos números. Pero, el nombre del juego como el de los números varían de tribu a tribu, algunos ejemplos de los cuales se pueden apreciar en el cuadro.

En los datos de Nordenskiöld hay una contradicción entre los nombres de los números y la manera de contar. El pretende que se cuente de acuerdo a las cifras que arrojan los "dados". El lanzamiento de los dados ocurre de la manera siguiente:

(10) “dass noch immer Spielbretter mit Rechenbrettern verwechselt werden [...] Ein Abakus, gleich wie er im einzelnen funktioniert, ist [...] ein "Rechner", das heisst, man gibt in ihn Zahlenwerte ein und erhält aufgrung vorgeschriebener Manipulationen die gewünschten Rechenergebnisse [...] Bereits aufgrund dessen lässt sich aussagen, dass Gegenstände mit mehr oder weniger tiefen Löchern sich nicht als Abakus eignen, weil die im Prozess des Rechnens erforderlichen Ersetzungen und Verschiebungen unnötig zeitaufwendig wären." 

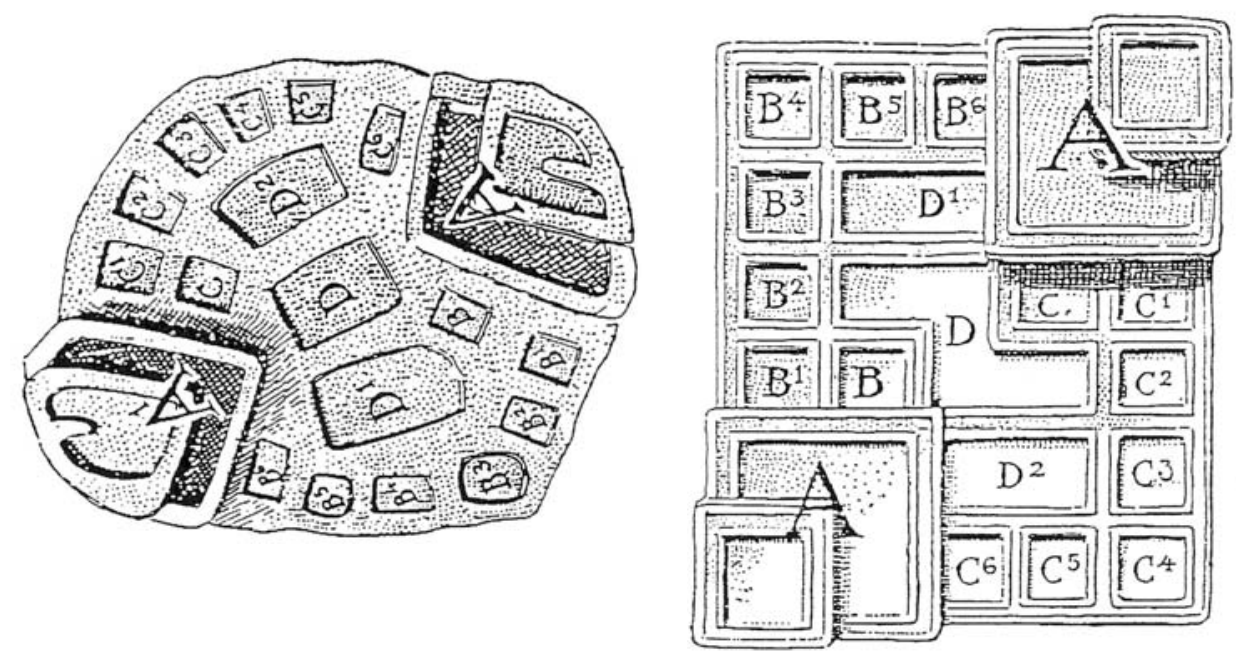

a - Spieltisch aus Stein, gefunden bei Cabana oder Urcon, Perú. Etwa $1 / 9$. (Tablero de piedra hallado cerca de Cabana o Urcon, Perú).

b - Spieltisch aus Holz von Patecte, Ecuador. Nac Rivet und Verneau. Etwa $1 / 9$. (Tablero de madera de Patecte, Ecuador. Según Rivet et Verneau).

Fig. 13 - Tableros según Nordenskiöld (1918: 170).

$\cap \cap \cap \cap=4 ; \cup \cup \cup \cup=2 ; \cap \cap \cup \cup=1 ;$

$\cap \cap \cap \cup=0 ; \cap \cup \cup \cup=0$.

4 konvexe Seiten nach oben gelten für 4

\begin{tabular}{|c|c|c|c|c|c|}
\hline n & " & " & $r$ & $n$ & " \\
\hline$\pi$ & ד & $r$ & $n$ & $" 7$ & 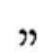 \\
\hline$\pi$ & $"$ & $\pi$ & $\pi$ & $r$ & $\pi$ \\
\hline$\pi$ & $r$ & " & $\pi$ & $r$ & $\pi$ \\
\hline
\end{tabular}

Lados convexos hacia arriba valen

Fig. 14 - Sacado de Vivante (1944: 216); Nordenskiöld (1910: 428). 


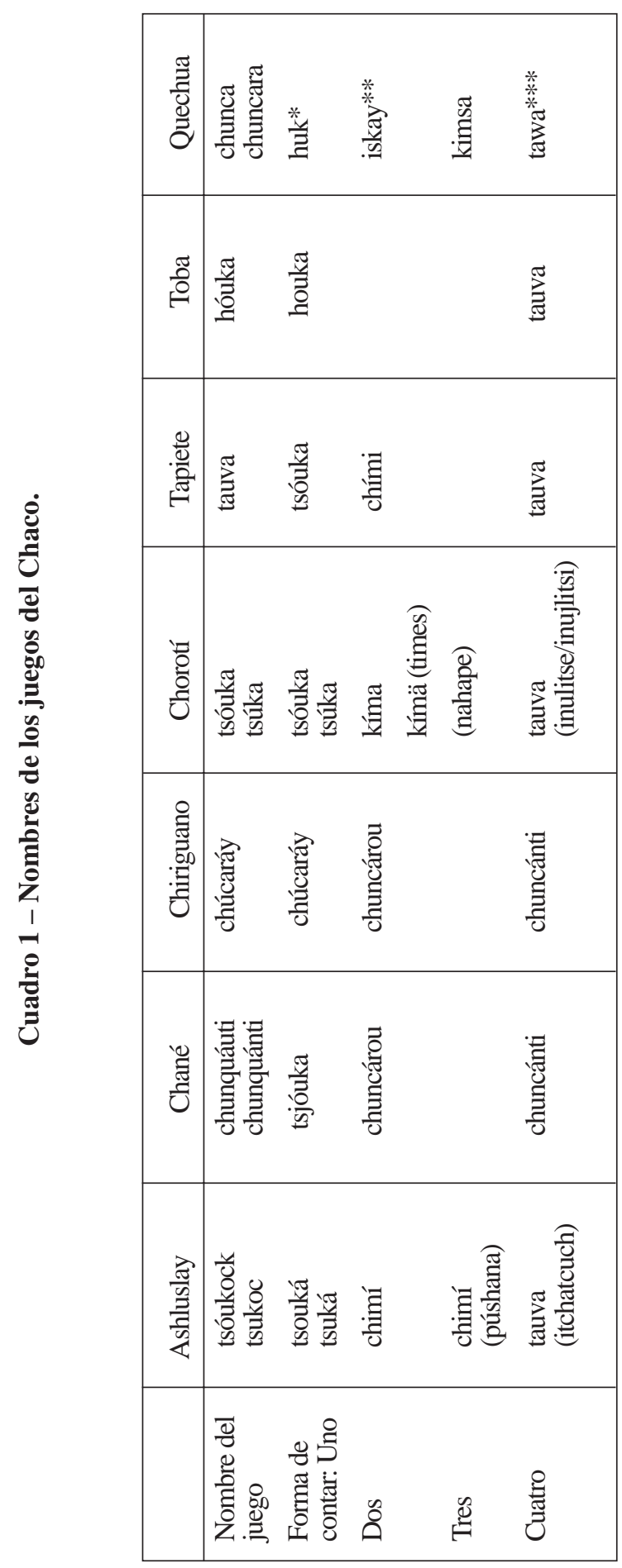

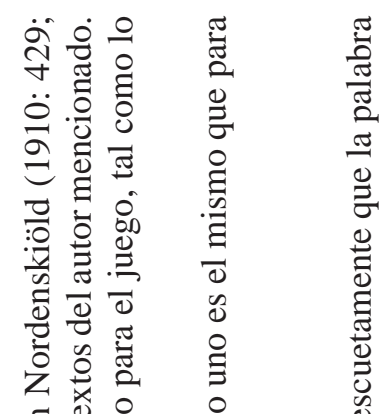

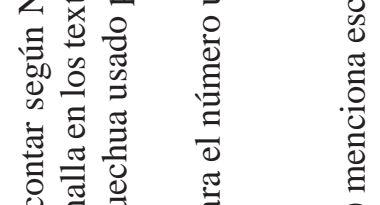

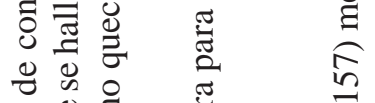

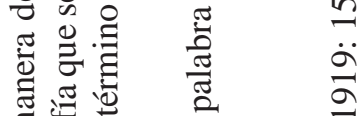

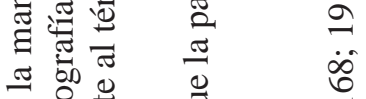

त

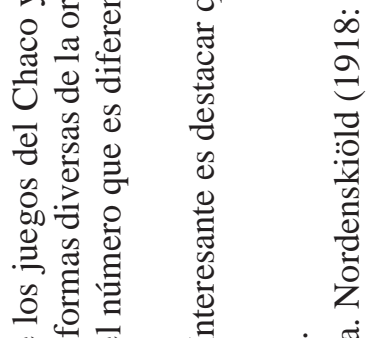

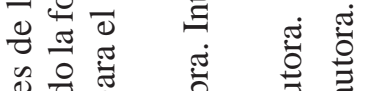

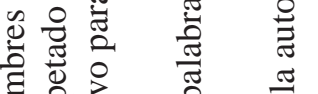

है

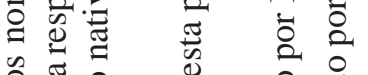

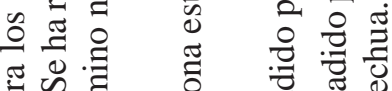

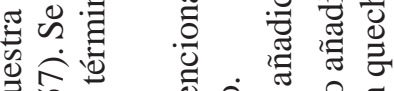

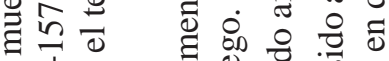

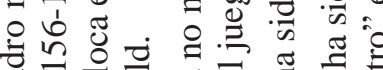

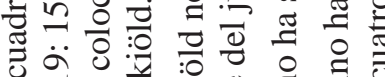

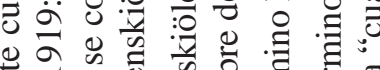

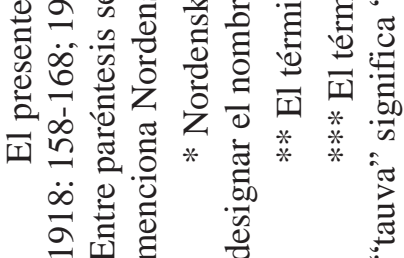


sosteniendo dos palos de juego en cada mano se arrojan los unos contra los otros (Nordenskiöld, 1910: 428; 1918: 167; 1919: 155). En la figura 14 se ve que no existe o no se usa la cifra 3 por lo cual Nordenskiöld explica de que esto es una característica común en todas las tribus del Chaco. Pero por los términos quechua que usaban en relación al juego y compilado en el cuadro adjunto, sabemos que el vocablo quechua kimsa para designar el tres estaba presente. Según Vivante, existen diversas maneras de contar, en las que los números 3 y 5 juegan un rol importante. Lamentablemente, Vivante no da los nombres nativos para tales números (Vivante, 1944: 215).

Del cuadro se infiere que si bien existen expresiones numéricas que tienen una analogía terminológica con el idioma quechua, sus significados sin embargo no corresponden del todo. Las palabras tsúka, chuncárou o chuncanti por ejemplo guardan afinidad con el término quechua chunca (diez), pero según su uso pueden significar cuatro, uno o dos. Las palabras chimi o kima muestran similitud con la palabra quechua kimsa (tres), pero puede designar tanto el tres como el dos. La palabra houk de los toba viene indudablemente del quechua huk (uno).

Otros términos que se asociaban con el juego también indican un origen andino como la palabra ápo. Como ya se mencionó, los indios chané usaban este término para nombrar los hoyos entre la "casa" y el "río". En quechua apo significa: rico, señor poderoso; a las deidades y los antepasados se les llama también así. Nordenskiöld no vio la coincidencia especialmente en este punto. En sus explicaciones no señala tanto el término apo como huk. No se quiere especular aquí por qué Nordenskiöld no nombra estos ejemplos, una aclaración posible sería un conocimiento rudimentario del quechua.

El etnólogo finlandés Karsten proporcionó en 1920 nuevos argumentos para el origen andino del juego. El observó el contexto del juego chuke o shuke que los indios choroti del Chaco jugaban en el mes de marzo,

“... [cuando] empieza el 'invierno' [período de seca]. Entonces comenzó de repente [el juego]. En todos los pueblos se tallaban los dados del chuke y lo jugaban cada día por horas, a veces desde la mañana hasta bien entrada la noche. Esto me daba la impresión que unas ideas místicas estaban conectadas con el juego. Además se jugaba siempre a una velocidad muy intensa, casi nerviosa, y el resultado de cada lanzamiento - sin importar que fuera tauva, chuke o kimä - siempre se exclamaba con voz alta, la cual se podía escuchar a mucha distancia.

Los choroti me explicaron que jugaban expresamente al chuke sólo a principios del 'invierno', cuando se agotaban el algarrobo y otras frutas comestibles del bosque. Entonces empezaba para los indios del Chaco un período en el que tenía que sostener una lucha dura por la subsistencia. El juego debía propiciar la multiplicación de las frutas y, en general, hacer ricos a los indios. Esto funciona por el hecho de que entre los jugadores siempre hay uno o algunos que ganan, lo que a manera mística favorece a todos." (Karsten, 1920: 102) (11) [la negrilla es de la autora]

(11) “[wenn] der 'Winter' [Trockenzeit] anfängt. Dann ging es auf einmal los. In allen Dörfern wurden chuke-Würfel geschnitten und das Spiel jeden Tag stundenlang, bisweilen von Morgen bis zum späten Abend, gespielt. Schon dies schien mir anzudeuten, dass mit diesem Spiel irgendwelche mystischen Vorstellungen verbunden waren. Ausserdem wurde immer in sehr intensivem, fast 
En 1930, Karsten añadió a su información lo siguiente:

"Los indios creen que ellos pueden influenciar el curso de la naturaleza, 'apurar' el crecimiento de las plantas por medio del tambor, bailes y remeciendo las sonajas. Así, en este período crítico, ellos piensan que pueden reforzar el poder vegetativo de los árboles de ulitidad para ellos y prevenir al mismo tiempo la hambruna jugando al shuke." (Karsten, 1930: 36-37) (12)

Las dos citas nombran elementos que están también presentes en el ornamento del tablero de juego de la época chimú:

- frutas maduras,

- el baile,

- objetos que se pueden interpretar como sonajas o cascabeles.

No se puede negar que llama la atención la semejanza en la forma de los campos de juego y su significado agrícola entre el tablero chimú y el juego del Chaco. Con todo lo expuesto podemos inferir en que el tablero chimú es la primera prueba material para la hipótesis del origen andino del juego del Chaco. Además, existen algunos otros argumentos, a los cuales queremos aludir, como el nombre mismo del juego.

\section{EL NOMBRE DEL JUEGO}

Cuando Nordenskiöld empezó a buscar pruebas en crónicas y notas etnográficas para sostener su hipótesis, casi no obtuvo éxito porque hasta entonces no se conocía de fuentes arqueológicas o documentales un utensilio de juego que mostrara las características del juego del Chaco. Por esta razón se esforzó en sacar conclusiones basadas en comparaciones entre los nombres tradicionales del juego de los indios del Chaco con la de los andinos.

Nordenskiöld escogió de los muchos nombres para este juego el término chunquanti, usual en el grupo chané, y lo relacionó con los datos de la crónica de Cobo (Nordenskiöld, 1918: 168; 1919: 156), que indican que en los Andes se conocía un juego con el nombre de chuncara. Se jugaba sobre una piedra plana o sobre una pieza

nervösem Tempo gespielt, und die Resultate jedes Wurfes - ob es nun tauva, chuke oder kimä war wurden jedesmal mit lauter Stimme, die weit umher gehört werden konnte, ausgerufen.

Die Choroti erklärten mir auch ausdrücklich, dass sie das chuke-Spiel nur zu Anfang des 'Winters' spielen, wenn der Algarrobo und andere essbare Früchte des Waldes knapp werden. Für die Chaco-Indianer beginnt dann eine Periode, wo sie oft einen harten Kampf ums Dasein zu bestehen haben. Das Spielen soll nun die Wirkung haben die Früchte zu vermehren und die Indianer überhaupt wohlhabend zu machen. Dies wird dadurch bewirkt, dass es unter den Spielern immer irgendeinen oder einige gibt, die gewinnen, was in mystischer Weise allen zugute kommt."

Compárese con Karsten, 1930: 36-37.

(12) "The indians believe that just as they can influence the course of the nature, "hurry on" the growth of the crops, by beating drums, dancing, and shaking rattles, so they believe that at this critical period they can enhance the vegetative power of the useful trees and prevent starving by playing shuke." 
de madera de cinco huecos. Para la marcación se usaban frijoles de diferentes colores, los cuales se iban avanzando de hoyo a hoyo, según el puntaje que los dados arrojaban:

“... Chuncara era otro juego de cinco hoyos pequeños cavados en alguna piedra llana o en tabla: jugábanlo con frijoles de varios colores, echando el dado, y como caía la suerte, los mudaban por sus casas hasta llegar al término; la primera casa valía diez, y las otras iban creciendo un denario hasta la quinta, que valía cincuenta." (Cobo 1964[1653], tomo 2, libro XIV: 270)

Como no existe mayor descripción del tablero, difícilmente podemos hacer alguna comparación con el juego del Chaco. La referencia al uso de tableros de madera es una coincidencia feliz. Sin embargo, el número de hoyos nos parece reducido, así como no sabemos dónde en los Andes se jugaba y en qué temporadas. Concluimos que estos detalles fueron omitidos deliberadamente por Cobo, ya que él señala que chuncara se jugaba para entretenerse y que se conocía como un juego de prendas, lo que hace suponer que probablemente se jugaba en cualquier época y que el juego era generalizado en los Andes, indicando que era uno de los más importantes aunque no aclara por qué.

Asimismo, Nordenskiöld menciona que Garcilaso usa la palabra chunca (diez) como palabra para designar "juego" en general, porque los indios "contaban en decenas" (Nordenskiöld, 1918: 168; 1919: 156). La hipótesis de Nordenskiöld se puede apoyar con los datos de otras fuentes de la época colonial, como del vocabulario de González Holguín, donde encontramos los términos como chunca y chuncana con los siguientes significados:

"Chunca. Diez.

Chuncana cuna. Los instrumentos de cada juego.

Chuncanaycuna. Qualquier juego de fortuna.

Chuncani. Iugar precio a juego de fortuna.” (González Holguín, 1989[1608]: 121)

Informaciones parecidas las hallamos en otros léxicos como el de Santo Tomás: "chungani. gui juego de fortuna.

chungasca cosa jugada.

chungani. gui jugar a los naypes.” (Santo Tomás 1951[1560]:274)

En la Gramática y Vocabulario del año 1603 se lee:

"chuncana. qualquier juego de fortuna.

chu[n]cani (13). jugar qualquier juego assi.

jugar precio. Chuncani” (Gramática y Vocabulario .... 1603: s/p)

(13) Abreviado en el original. 
La acepción chunca como juego se encuentra incluso en la lengua aymara:

"Chunca; Tagua de madera para jugar.

Chuncasitha, Piscasitha; jugar a la tagua, que aca es de madera.

Chuncasitha, Marccasitha. Perder a este juego.

Chuncajasitha. Vencer" (Bertonio, 1984[1612]: 92)

Por lo anterior inferimos que las palabras chunca, chuncana, pueden indicar tanto el utensilio de juego como también "juego" en general, mientras que el término chuncani señala el nombre de un juego de azar o la acción misma de jugar. Es evidente que chuncani o chuncana se pueden entender, asimismo, como términos generales para juego de prendas o juego de azar. En este sentido hay correspondencia con los datos del Chaco y con Cobo, aunque lamentablemente los vocabularios no nos describen cómo se jugaba. Pero baste aquí la similitud en las denominaciones para pensar al igual que Nordenskiöld que el juego del Chaco tiene un origen andino.

En cuanto a los otros términos usados, no hallamos referencia para houk ni para tauva. El léxico de Bertonio incluye la palabra tagua, que se entiende como el nombre español de un juego (véase los ejemplos aymaras anteriores); y lo cita como posibilidad de comparación con el juego nativo chuncasitha (Bertonio 1984[1612]: 92). Tauva y sus variantes escritas como tahua y tagua no se hallan anotadas en ningún vocabulario quechua colonial. Solamente en la sección de las palabras españolas de Bertonio se halla la entrada tagua:

"juego de la Tagua; Ccanccallu

jugarle ccanccallusitha.

tagua de huesso: Ccancalla

jugarla: Ccanccallusitha" (Bertonio, 1984[1612]: 441)

El hecho de que el vocablo tagua reciba aquí una traducción aymara, apoya mi suposición de que tagua era un juego español. Asimismo, Emilia Romero, en su estudio sobre los juegos de los Andes, nombra la tagua entre los juegos venidos de España. Ella afirma que poco después de la conquista, muchos juegos europeos fueron adoptados por los indios, y como la mayoría de las descripciones sobre juegos indígenas se realizaron recién 70 a 100 años después de la conquista, se hace imposible entonces distinguir cuál juego es realmente indígena. Para Romero, se hace así muy difícil hacer una reconstrucción correcta de los juegos indígenas (Romero, 1943: 11-12). Un conocimiento más profundo de los juegos españoles de los siglos XVI y XVII podría esclarecer el panorama de los juegos andinos coloniales.

Nordenskiöld nos proporciona una serie de nombres que se usa en relación al juego descrito por él del Chaco. Ya hemos visto que efectivamente la palabra del Chaco chuncanti ha de derivarse del término quechua chuncana, el que designaba aparentemente "juego" en general, o más específicamente "juego de azar". Pensamos que debió haber existido en los Andes una palabra más precisa que designare el juego ritual descrito que se repetía todos los años para la época del fin de las lluvias y comienzo 
de la cosecha. Solamente la crónica de Guaman Poma nos da informaciones calendáricas en relación de las cuales nos menciona también los juegos que se celebraban. Así, durante el período de maduración de los frutos, es decir, al final de la época de lluvias o comenzando la época de seca en:

“... todo el mes [abril] juegan los prencipales al juego - de riui - choca - al uayro de ynaca - pichica de hilancula - y de challcochima y juegan otros juegos y rrecocijos [sic]" (Guaman Poma, 1936[1613]: 243)

La lista de Guaman Poma no es completa, pero valga aquí la mención del juego choca, que concuerda fonéticamente con el juego chuke o shuke registrado por Karsten entre los indios chorotí del Chaco, como se dio a conocer anteriormente. Esta coincidencia nos sugiere que muy probablemente sea chuke, choca o chuka el nombre verdadero del juego ritual andino que llegó al Chaco y que hasta principios del siglo XX allí perduraba, mientras en los Andes parece haber desaparecido.

Si bien Guaman Poma no describe ningún juego, el contexto y la fecha en que se jugaban nos hace pensar que cualquiera de los juegos indicados por el cronista indio tenían un carácter ritual. Quisiéramos explorar aquí la posibilidad de alguna similitud de algún juego aparte del chuke o chuka con el juego del Chaco. No hemos hallado datos para los juegos riui y challcochima. Para el juego uayro de ynaca (yñaca) hallamos las asociaciones siguientes. La palabra yñaca significa en aymara "Palla; mujer que viene de casta noble de los Ingas" (Bertonio, 1984[1612]: 175) y en quechua "La mantellina de la cabeça" (González Holguín, 1989[1608]: 368). En el vocabulario aymara de Bertonio se encuentra además la siguiente entrada: "Iñacatatha; Passar de vna rivera a otra." (Bertonio, 1984[1612]: 176) Quizá sea este término una alusión al juego del Chaco que tiene en el medio un río en sentido figurado, como ya se mencionó, y el que los jugadores tienen que pasar de una orilla a la otra.

Hilancola es una palabra aymara, la que correctamente debe escribirse halancola. Es posible que se trate de un error de anotación de Guaman Poma. Según Bertonio, halancola significa "adelantar cuando se juega", es decir, no es nombre de juego, sino que durante un

“... juego que se parece algo al de las tablas, y van adelantando las casas con estas palabras, Halancola: y a su traça llaman Aucattaca: y al dado de madera de que usan, Pisca.+ jugarle Pisacasitha, Chuncasitha, Huayrusitha, Huncusitha." (Bertonio, 1984[1614]: 273-274)

Por lo visto se usa el término halancola para los juegos pisca, chunca, huayru y huncu. Halancola está relacionado con la palabra que se halla también en Guaman Poma, o sea, pisca o pichica. En las crónicas coloniales como en los trabajos etnográficos actuales se encuentran datos sobre los juegos rituales pichica (pichca) y uayro (wayru) que Guaman Poma refiere. Ciertas descripciones del pichca y wayru admiten comparaciones con el juego del Chaco, pues se diferencian de aquél un tanto por la naturaleza como la ocasión del juego. Veamos qué nos dicen los vocabularios quechuas sobre los dos juegos: 
"Ppichca. Vn juego como de dados.

Pichcana. Vn palo seysauado con que juegan.

Ppichcani ppichccaccuni. Iugar este juego.

Huayru, o ppichcca. Iugo de la Naturales.

Huayru. El mayor punto, o el mejor que gana." (González Holguín, 1989[1608]: 196, 284)

"Guayroni. gui

jugar juego de fortuna

Guayroc çapa jugador deste juego.” (Santo Tomás, [1560] 1951: 283)

En la crónica de Murúa se encuentra para pichca el dato siguiente:

“... jugaban estos indios con un solo dado, que llaman la pichca, de cinco puntos por un lado, uno por otro, dos por otro y por otro tres, y el lado cuatro, y la punta con un cruz vale cinco, y el suelo del dado, veinte, y así se juega hoy en día, y esto lo usan así los indios como las indias; aunque fuera de conejos, que ellos llaman cuyes; no juegan cosas de plata.

[juego] questos indios llaman la pisca, con su tabla y agujeros o señales donde iban pasando los tantos; la pisca es como una perinola, aunque no se anda, antes arroja y descubre el punto, como la taba o dados." (Murúa, citado en Hartmann, 1980: 226)

Según el informe de Cobo, pichca es parecido a un juego de dados en el que sólo se juega con un dado de cinco puntos. Huayru o guayro (wayru) es el mismo juego que la pichca, en el que el número uno tiene el nombre de Guayro en recuerdo de una noble dama inca (Cobo 1964[1653], tomo 2, libro XII: 86; libro XIV: 270). Esta información coincide con el dato anterior de Guaman Poma, quien menciona al uayro de yñaca como un juego ritual, porque ya vimos que yñaca significa "dama inca". Probablemente Guaman Poma quiere decir con uayro de yñaca lo mismo que "juego de la noble dama inca". Aparte de que suponemos de que se trate de un juego ritual porque Guaman Poma lo menciona entre los juegos que se juegan en esa fecha calendárica de fines del período pluvial, los otros datos coloniales mencionados no corroboran el carácter ritual y más bien lo consideran como otro juego de azar. Pero, muy probablemente por ser un juego de fortuna, que en español se interpreta también como "destino", estos juegos podían tener múltiples usos, ya sea ritual o laica, según la situación y la ocasión. Sin embargo, parecen haberse jugado tanto con tablero como sin tablero de juego.

Una vez más carecemos de datos explícitos sobre los utensilios de juego o una descripción del juego que permitan establecer una afinidad con el juego del Chaco, una vez se menciona el uso de un solo dado, otros de dados, otros de palos de juego (Hartmann, 1980; Hartmann \& Oberem, 1968; Hocquenghem, 1979: 337; 1987: 151153; Karsten, 1920: 75-85; 1930: 7-9; 1931; Nordenskiöld; 1930; Romero, 1943: 1921). Para la época colonial sólo se cuenta con la referencia de Murúa de un tablero de juego (ver cita anterior), el que posee escaso valor informativo. Actualmente existe en 
determinadas regiones, como por ejemplo en el Ecuador, un campo de juego con piedras de marcación (Hartmann \& Oberem, 1968: 243-245). Sin embargo, la distribución de los huecos en el campo de juego es distinta a la del juego del Chaco y al del tablero chimú. A pesar de la carencia de datos precisos, todos los indicios nos conducen a la misma conclusión de Nordenskiöld sobre el origen andino del juego.

\section{USO RITUAL DEL JUEGO}

Ya vimos que el juego chuncana o chuke del Chaco es jugado de forma ritual a finales de la época de lluvias. Para los Andes encontramos que Guaman Poma nos indica que en la colonia se jugaba muchos juegos durante la temporada indicada. Tenemos el dato concreto que en la costa norte del Perú, o sea en la región donde se desenvolvió la cultura Chimú, se conocían en la época prehispánica juegos que estaban en una relación directa con la fertilidad vegetal y con los ancestros.

Hace años que Anne Marie Hocquenghem se dedica al estudio de los calendarios rituales de la región andina, dentro del marco de sus investigaciones sobre la iconografía mochica. Ella llega a la conclusión que determinados juegos tienen que ver con rituales de fecundidad.

"Jouée par des ancêtres mythiques, elle [la scène] est à considérer comme un acte d'instauration, le modèle d'un rite à perpétuer. Jouée par des hommes, elle [la scène] peut à la fois avoir le sens d'un rite agraire qui tend à assurer la fertilité animale et végétale et d'un rite de passage, qui tend à faciliter la traversée des différentes étapes de la vie." (Hocquenghem, 1979: 329)

Según la autora, los juegos sirven además para establecer la comunicación de los hombres con el mundo de los antepasados:

"El rito agrario y el rito de duelo indican que el juego tiene una función en el marco de los intercambios entre los hombres y los ancestros y difuntos. Tiene también una función en el marco de la redistribución de los bienes de la comunidad." (Hocquenghem, 1987: 155)

Referencias concretas adicionales para el uso ritual de los juegos andinos lo hallamos en otras fuentes coloniales y etnográficas. En la región andina, los modernos juegos wayru y pichca tienen relación con el entierro. Los dos juegos cumplen varias funciones a la vez: reconocer la última voluntad del muerto, dividir la herencia y mantener la velada del difunto con juegos (Hocquenghem, 1987: 150-153). De la época colonial sólo se conoce una información parecida: la de Arriaga en el siglo XVII (14), que dice que pichca es un juego que impide conciliar el sueño durante la velación del difunto:

(14) Hartmann (1980: 228) opina que los datos del informe de Juan y Ulloa del siglo XVIII sobre el juego pasa son una referencia directa al juego en los rituales de la muerte. 
“... y juegan al juego que llaman la Pisca, tomando el nombre de los cinco días, que es con unos palillos con diversas rayas, y no entiendo qué tienen más misterio que para divertir el sueño, y al cabo de estos cinco días van a lavar la ropa que dejó el difunto al río." (Arriaga, 1968[1621], cap. VI: 216)

Todo parece indicar que pichca y wayru fueron utilizados tanto para ritos de entierro — siendo aún usados en ese contexto - como para ritos agrarios de fertilidad. Esto no excluye los datos de los autores anteriormente nombrados, sino que los complementa.

Un revisión del vocabulario muchik, idioma que se hablaba aún a principios del siglo XX en la costa norte del Perú, no nos permite sacar nada en conclusión con respecto a la idea de juegos rituales:

“De ñeñein, ñeñaz, ñeñædoiñ, por jugar, sale

ñeiñ mæd, ñeiñ mædeio, 1. ñeiñ, mædeb, jugar en compañia.

Ñe; ñieñ, ñieñaz, ñie ñædoiñ, ñie ñædd: jugar.” (Carrera, 1939[1644]: 24, 71)

“kosll, koslleiñ, kosllenäm, kutsäd, jugar.” (Middendorf, 1862: 88)

\section{MODO DE JUGAR}

Una reconstrucción del modo de jugar solamente se puede hacer a base de la información proveniente del Chaco. Según Nordenskiöld, los indios chané jugaban de la siguiente manera (véase para ello la Fig. 1):

"En éstos [hoyos de partida \# 1 y 23] se colocan al principio del juego, dos varillas puntiagudas [...] Si empieza [el jugador A] y echa por ejemplo un 2, mete la varilla en el hueco 3, si echa otro 1 pasa la varilla al hueco 4, y así sucesivamente. Así continúa hasta que eche una vez el 0 , y entonces empieza [el jugador] $\mathrm{B}$ hasta que también eche el 0, etc. Llega A a pasar el hueco 12 y B se queda antes del hueco 12, entonces A va removiendo las varillas del contrario según va llegando a los huecos de éste. Así se va siempre de un lado para el otro y se da la vuelta en las casas. Si se encuentra uno con el palito de marcación del otro, éste se saca y el contrincante tiene que continuar desde el hueco donde todavía tiene una varilla. No se sacan todavía las varillas de la casa del contrincante hasta que se hallan retirado todas las varillas de ése. Si se han retirado todas la varillas en juego del contrario, entonces se pueden retirar los palitos marcadores que se hallan en la casa del contrincante. El que lo logra gana el juego. Si durante el juego alguien llega al hueco 12, o sea que cae al agua o al "río" y no puede salir de allí con el lanzamiento siguiente, sino echa un 0 , entonces tiene que empezar desde el sitio donde está el palito más cerca a su casa. Si sólo quedan dos palos de marcación y el uno "cae al agua", el juego resulta empatado." (Nordenskiöld, 1910: 428-429) (15)

(15) "In diese [Anfangslöcher Nr. 1 und 23] werden beim Anfang des Spieles zwei spitze Stäbchen gesteckt. [...] Fängt A an und wirft z.B. 2, so steckt er das Stäbchen in 3, wirft er 1 dazu in 
Nordenskiöld señala que el juego del Chaco también era jugado por varios participantes (Nordenskiöld, 1910: 428). Sin embargo, su descripción sólo se ajusta a dos jugadores. El campo de juego muestra además sólo 2 orificios de partida. Como el tablero de juego chimú tiene 5 hoyos de partida en la figura del jaguar (Fig. 11), es de suponer que de 2 a 10 jugadores podían participar al mismo tiempo. Tampoco Nordenskiöld especifica cuántas varillas podía usar cada jugador.

Vivante, Kutscher y Hissink creyeron reconocer tal curso del juego en los dibujos de la vasijas mochicas (Vivante, 1942: 279-280; 1946; 1948: 250; 1958-1959; Kutscher, 1950: 79-80; Hissink, 1952: 121-125). El problema de esta identificación es que en tales dibujos es muy difícil determinar qué tipo de juego fue reproducido (Figs. 15a y b), por ejemplo, no sabemos cómo era el campo de juego. Lo único que se puede constatar claramente es el uso de los nombrados palos o "dados" de juego (compárese Figs. 2 y 15) y los hoyos en el suelo.

Sin embargo, ya vimos que Hocquenghem detecta que los mochica también jugaban con una finalidad ritual. Así, tenemos un principio común de los chimú, de los mochica y de los indios del Chaco: la conexión con los antepasados o deidades, para cuya protección se luchaba o se jugaba.

No es seguro si los chimú jugaban de la manera antes mencionada. Pero es interesante constatar que las reglas de juego del Chaco son perfectamente aplicables al tablero chimú, sin necesidad de ninguna variación. Esto sería un indicio más que corrobora la tesis de Nordenskiöld (16).

Aparte, debido a la forma del tablero chimú se puede afirmar que se jugaba de dos maneras y en dos ocasiones. De una forma de juego, el hoyo del medio (señalado por la ranura) juega un rol como el "río" en el campo de juego del Chaco (Fig. 1). En la otra forma de juego, el "río" no aparece (Fig. 7). La falta de incisión puede indicar que en un tiempo o temporada se jugaba una variante del juego. Una reconstrucción de esta variante del juego no es posible. ¿Por qué existen dos lados que sugieren dos variantes del juego? Se ofrece aquí la siguiente hipótesis. Según Hocquenghem, como ya se explicó más arriba, en el curso del calendario ritual la comunicación con los antepasados desempeña un papel importante. Los ancestros se preocupaban por la fertilidad del suelo, por la lluvia y la madurez de las plantas. Al principio del período

\footnotetext{
4 usw. A setzt so lange fort, bis er einmal 0 wirft, dann beginnt B, bis auch er 0 wirft usw. Kommt A über 12 und B unter 12, so schlagen sie die Halme auf die entgegengesetzte Seite hinaus in die Löcher, in die sie kommen. Es gilt zuerst alle Halme auf der Seite der Gegner zu schlagen. Man geht immer von der einen Seite bis zur anderen und kehrt in den Häusern um. Trifft man den Markierstock des anderen, wo wird dieser herausgeschlagen und muss wieder von vorn anfangen, jedoch nicht in seinem Hause, sondern auf dem nächsten Platz, wo noch ein Halm liegt. Dieser wird dann herausgeschlagen. Hat man alle Halme auf der Seite des Gegners herausgeschlagen, so hat man den Markierstock des anderen herauszuschlagen. Gelingt einem das, so hat man gewonnen. Kommt jemand während des Spieles auf 12, d.h. fällt er ins Wasser und kann mit dem folgenden Schlage nicht aus demselben herauskommen, sondern wirft 0 , so muss er bei dem Halme der seinem Hause am nächsten steht, anfangen. Sind nur die beiden Markierstöcke übrig und "fällt" der eine "ins Wasser", so ist das Spiel unentschieden."
}

(16) Agradezco a la arqueóloga Inés de Aguila, del Instituto Riva-Agüero por haberme llamado la atención sobre este aspecto importante. 


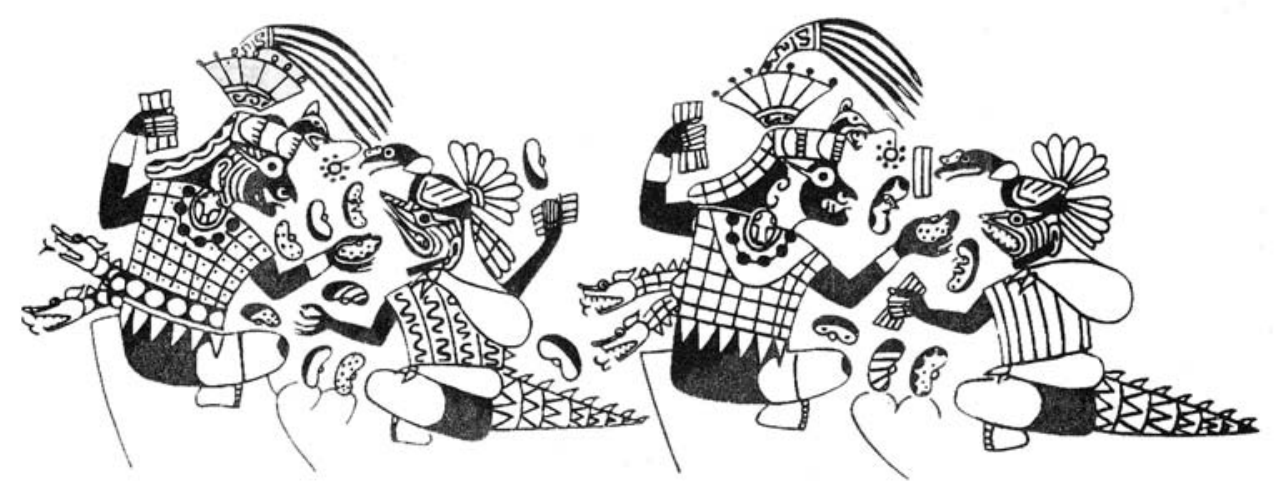

Fig. 15a - Sacado de Hocquenghem (1987: figura 159).

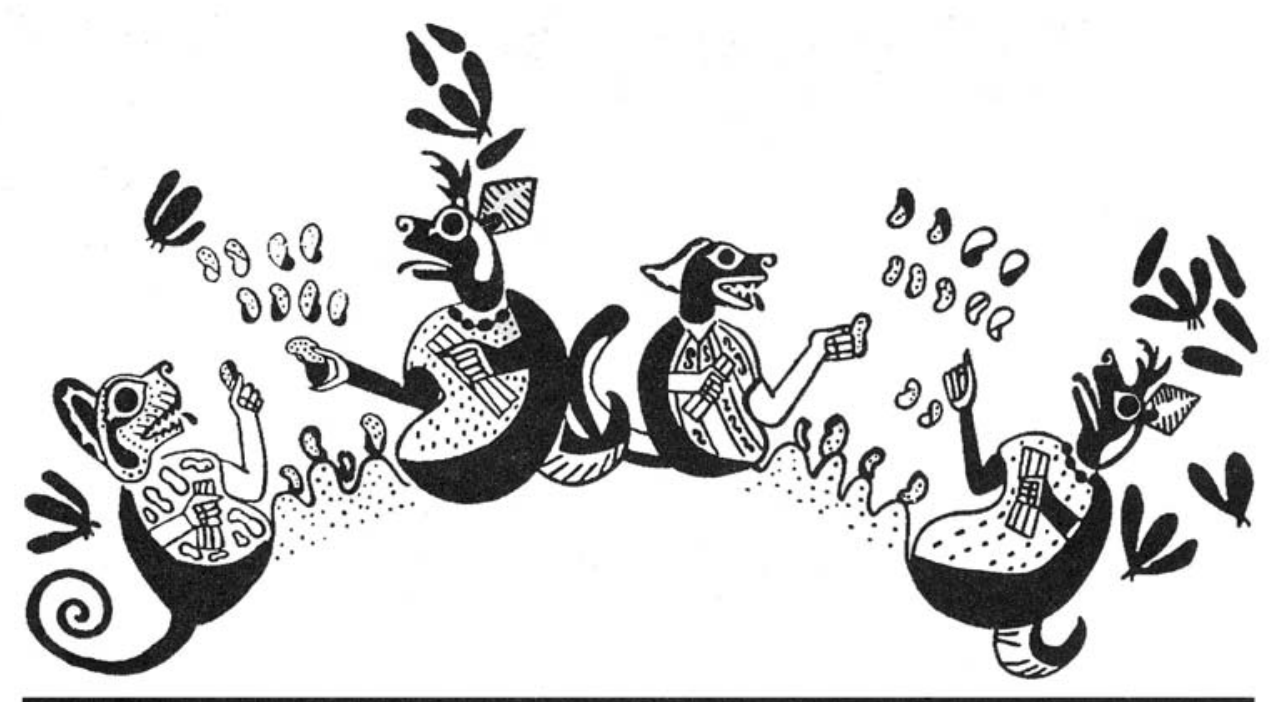

Fig. 15b - Sacado de Hocquenghem (1987: figura 160). 
de lluvias, o sea, en octubre o noviembre, son llamados desde el más allá para ayudar a los hombres; al final de este tiempo, o sea, en marzo o abril, son despedidos (Hocquenghem, 1987: 86-99, 138-141, 144-156). Bajo este aspecto quiero destacar que el utensilio de juego chimú muestra las figuras con la cabeza en dirección hacia el cielo, es decir, con el lado de los hoyos sin incisión, lo que estaría dando a conocer que la variante del juego se jugaba cuando los antepasados salían del inframundo que correspondería al comienzo de la época de lluvias.

Cuando se voltea el tablero chimú para el lado donde la incisión o el "río" juega un rol en la variante del juego, entonces las figuras de los ancestros se hallan con la cabeza para abajo, simbolizando así el regreso al inframundo. Con esto se constata una gran coincidencia con el fin de la época de lluvias y el comienzo de la cosecha, motivo por el cual se jugaba en el Chaco. Así vemos que una variante del juego sin incisión servía para llamar a los antepasados, mientras que para despedirlos servía la variante con incisión, variante del juego que probablemente se jugaba según las reglas del juego del Chaco. El tablero del juego chimú tenía entonces una doble función.

\section{CONCLUSIONES}

El objeto de madera chimú es un tablero de juego y representa la prueba concreta de la tesis de Nordenskiöld sobre el origen andino del juego del Chaco. Las coincidencias se muestran en una distribución igual de los hoyos, en los nombres quechua que designan juego y números, en el motivo ritual del juego y en la practicabilidad de las reglas del juego del Chaco aplicables al tablero chimú. Por consiguiente, el utensilio chimú ha de considerarse un precusor del juego del Chaco. El juego se extendió y se mantuvo por mucho tiempo por su finalidad religiosa.

Mientras que el utensilio del juego chimú tenía una doble función dentro del calendario ritual, es decir, que era usado tanto al principio como al final del período de lluvias, los indios del Chaco la jugaban principalmente sólo al final del período de lluvias, o sea al principio del período de sequía con una intención mágico-religiosa. Parece que los juegos rituales al principio de la época de lluvias corresponden a una tradición litoral, pues no hay indicios sobre juegos en la misma época en la sierra, basándonos en el único dato proveniente de Guaman Poma. Así se explicaría por qué los indios del Chaco sólo aplican el juego al principio del período de sequía o fines de la temporada de lluvias. Una mayor lectura e interpretación de la iconografía del tablero nos dará más información sobre los juegos y creencias chimú. En particular, todavía nos falta dilucidar el significado de los cuadrados con las cruces y las aspas, y las figuras cónicas situadas entre las figuras humanas. Asimismo, un análisis del tipo de madera nos podría dar un indicio del lugar de origen del objeto.

Aunque conocemos los nombres quechuas del juego como chuncana o chuke, que fueron adoptados por los indios del Chaco, desconocemos por completo el nombre original en muchik que era probablemente la lengua hablada por los chimú.

En general, son necesarias más investigaciones y datos arqueológicamente fundados para cerrar el vacío de espacio y tiempo entre el juego de la cultura chimú y el juego de los indios del Chaco del presente. 


\section{Referencias citadas}

ARRIAGA, P. J. de, 1968[1621] - Extirpación de la idolatría del Pirú. In: Crónicas Peruanas de Interés Indígena: 191-277; Madrid: Atlas. Biblioteca de Autores Españoles, tomo 209.

BERTONIO, L., 1984[1612] - Vocabulario de la Lengua Aymara (1612), 946p.: Cochabamba: Centro de Estudios de la Realidad Social, Instituto Francés de Estudios Andinos, Museo Nacional de Etnografía y Folklore. Reimpresión Facsimilar.

CARRERA, F. de la, 1939[1653] - Arte de la Lengua Yunga; Tucumán: Universidad Nacional del Tucumán, Instituto de Antropología. Publicación № 256.

COBO, B., 1964[1653] - Historia del Nuevo Mundo. In: Obras del P. Bernabé Cobo de la Compañía de Jesús, Tomo II: 5-275; Madrid: Atlas. Biblioteca de Autores Españoles, tomo XCII.

ESPINOZA SORIANO, W., 1987 - Artesanos, transacciones, monedas y formas de pago en el mundo andino. Siglos XV y XVI. Tomo 1, 213p.; Lima: Banco Central de Reserva del Perú.

FIGGE, H., 1987 - Rechnen mit dem peruanischen Abakus. Spielen mit dem Objekt DB-02MRI. Versuch einer Rekonstruktion von Regeln. Indiana, vol. 11: 143-165; Berlin.

GONZÁLEZ HOLGUÍN, D., 1989[1608] - Vocabulario de la Lengua General de todo el Peru llamada Lengua qquichua o del Inca, 707p.; Lima: Universidad Nacional Mayor de San Marcos. Edición facsimilar por Ramiro Matos.

GRAMÁTICA..., 1603 - Gramática y vocabulario en la lengua del Peru llamada Quichua, y en la lengua española; Impreso en Sevilla en casa de Clemente Hidalgo.

GUAMAN POMA DE AYALA, F., 1936[1613] - Nueva Corónica y Buen Gobierno, xxviii + 1167p.: Paris: Travaux et Mémoires de l'Institut d'Ethnologie, 23.

HARTMANN, R., 1980 - Juegos de velorio en la sierra ecuatoriana. Indiana, vol. 6: 225-274; Berlin.

HARTMANN, R. \& HOLM, O., 1985 - Zur sogenannten "romana" im Andengebiet. Zeitschrift für Ethnologie, vol. 110, $\mathbf{n}^{\circ}$ 2: 239-251; Berlin.

HARTMANN, R. \& OBEREM, U., 1968 - Beiträge zum "Huairu-Spiel”. Zeitschrift für Ethnologie, vol. 93, $\mathbf{n}^{\circ}$ 1-2: 240-259; Braunschweig.

HISSINK, K., 1952 - Motive der Mochica-Keramik. Paideuma, Mitteilungen zur Kulturkunde, $\mathbf{n}^{\circ}$ 5: 115-135; Bamberg.

HOCQUENGHEM, A. M., 1979 - Le jeu et l'iconographie mochica. Baessler-Archiv, vol. 27: 325-345; Berlin.

HOCQUENGHEM, A. M., 1987 - Iconografía mochica, 280p. + illust.; Lima: Pontificia Universidad Católica del Perú. Segunda edición.

INKA-PERU, 1991 - Inka-Peru. Indianische Hochkulturen durch drei Jahrtausende. Tomo 2. Kataloge del OÖ. Landesmuseums. Neue Serie, $n^{\circ} 41$; Linz

KARSTEN, R., 1920 - Beiträge zur Sittengeschichte der südamerikanischen Indianer. Abhandlung III: 73-104; Åbo/Helsingfors: Åbo Akademi. Acta Academiae Aboensis Humaniora 1:4.

KARSTEN, R., 1930 - Ceremonial games of the South American Indians. Societas Scientiarum Fennica. Commentationes Humanarum Litterarum, vol. III, $\mathbf{n}^{\circ}$ 2: 1-38; Helsingfors.

KARSTEN, R., 1931 - My Huairu Game once more. Societas Scientiarum Fennica. Commentationes Humanarum Litterarum, vol. III, $\mathbf{n}^{\circ}$ 7: 1-11; Helsingfors.

KUTSCHER, G., 1950 - Chimu, eine altindianische Hochkultur; Berlin: Gebr. Mann.

MCCLELlAND, D., 1990 - A maritime passage from Moche to Chimu. In: The Northern Dynasties. Kingship and Statecraft in Chimor (Michael Moseley \& Alana Cordy-Collins eds.): 75-106; Washington: Dumbarton Oaks Research Library and Collection. A Symposium at Dumbarton Oaks, 12th and 13th October 1985. 
MIDDENDORF, E.W., 1862 - Das Muchik oder die Chimu-Sprache; Leipzig: Brockhaus. Die einheimischen Sprachen Perus, vol. 6.

NORDENSKIÖLD, E., 1910 - Spiele und Spielsachen im Gran Chaco und im Nordamerika. Zeitschrift für Ethnologie, vol. 42: 427-433; Berlin.

NORDENSKIÖLD, E., 1918 - Spieltische aus Peru und Ecuador. Zeitschrift für Ethnologie, vol. 50: 166-171; Berlin.

NORDENSKIÖLD, E., 1919 - An Ethno-Geographical Analysis of the Material Culture of two Indian Tribes in the Gran Chaco. In: Comparative Ethnographical Studies I. Cap. 23: Games and Playthings: 153-163; Göteborg.

NORDENSKIÖLD, E., 1930 - Huayru Game. Journal de la Société des Américanistes, tome 22: 211-213; Paris.

RIVET, P. \& VERNEAU, R., 1912 - Ethnographie ancienne de l'Équateur. Mission du service géographique de l'armée pour la mesure d'un arc de méridien équatorial en Amérique du Sud, tome 6; Paris.

ROMERO, E., 1943 - Juegos del Antiguo Perú. Contribución a una historia del juego en el Perú; México: Ediciones Llama.

SANTO TOMÁS, D. de, 1951[1560] - Lexikon o Vocabulario de la Lengua General del Peru, xxxii + 374p.; Lima: Universidad Nacional Mayor de San Marcos. Facsímil. Edición del Instituto de Historia.

SMITH, J. W., 1977 - Recuay Gaming Boards: A Preliminary Study. Indiana, vol. 4: 111-137; Berlin.

VIVANTE, A., 1942 - El juego mochica con pallares. Revista Geográfica Americana, tomo 18, $n^{\circ}$ 110: 275-280; Buenos Aires.

VIVANTE, A., 1944 - Un juego de azar indígena. Revista Geográfica Americana, tomo 21, ${ }^{\circ}$ 127: 235-216; Buenos Aires.

VIVANTE, A., 1946 - Un juego antiguo peruano. Revista Geográfica Americana, tomo 26, $\mathbf{n}^{\circ}$ 154: 27-33; Buenos Aires.

VIVANTE, A., 1948 - A propósito de dos juegos indígenas. Revista Geográfica Americana, tomo 29, $\mathbf{n}^{\circ}$ 177: 245-251; Buenos Aires.

VIVANTE, A., 1958-1959 - Paráfrasis a un tema decorativo mochica. Runa, vol. 9, partes 1-2: 345-377; Buenos Aires. 
Institut Français d'Études Andines - Centro Amazónico de Antropología y Aplicación Práctica

Pedidos: IFEA, Casilla 18-1217, Lima 18 -Perí, Tel. 4476070 Fax: 4457650 - E-mail: postmasterlifea.org.pe

Web: http://www. ifeanet.org 